\title{
GRUPILLO, Arthur. 0 homem de gosto e o egoísta lógico: uma introdução crítica à estética de Kant. São Paulo: Edições Loyola, 2016.
}

\section{Matheus Silva Freitas ${ }^{1}$}

O bomem de gosto e o egoísta lógico surgiu, a princípio, como tese de Mestrado em Filosofia de Arthur Grupillo, pela UFMG. A dissertação foi indicada pela ANPOF, no biênio 2006-2007, ao prêmio de melhor tese e dissertação. Atualmente professor adjunto da Universidade Federal de Sergipe, após doutoramento com estágios de pesquisa nas Universidades de Kassel e Frankfurt am Main, e focado em temas da estética e do pensamento pósmetafísico, o pesquisador lança uma versão revisada e aperfeiçoada daquele texto.

A comunidade acadêmica passa a ter acesso, desde então, ao que o próprio autor chama de "uma apreciação sistemática do pensamento estético kantiano" (GRUPILLO, 2016, p. 12), direcionada a estudantes de graduação, pós-graduação e mesmo professores de estética. O livro tem como tema central o problema da comunicabilidade dos juízos estéticos puros, ou, na formulação mais popular dada por seu autor: "gosto se discute? " Sim ou não, acontece que, quando alguém está engajado numa discussão sobre a beleza de algo, pretende granjear a concordância de todos os seus interlocutores, ou nem se esforçaria por argumentar; entretanto, poucas pessoas estão dispostas a assumir que o gosto obedeça a padrões objetivos. Tornando mais uma vez ao vocabulário kantiano, dessa vez para não mais se afastar dele, Grupillo nota que a solução para tal problema encontra sempre a seguinte obstrução: como oferecer ao juízo estético uma fundamentação de validade universal, sem abrir mão de atribuir a esses mesmos juízos uma dimensão empírica, indissociável da experiência estética? O grande esforço filosófico de Kant para responder essa questão encontra, no livro de Grupillo, uma reconstrução analiticamente

${ }^{1}$ Graduando em Filosofia pela Universidade Federal de Sergipe, bolsista de iniciação científica PIBIC/FAPITEC (2016-2017), com projeto sobre "A crítica de Schopenhauer a Hegel: idealismo e pessimismo". 
rigorosa e bastante técnica, embora dificilmente definitiva, conquanto sua monografia seja uma das primeiras a tratar do assunto em língua portuguesa.

A empreitada começa com um resumo das abordagens filosóficas sobre a estética, no período imediatamente anterior à fase "Crítica" de Kant. São trazidos ao debate, então, Edmund Burke, como paradigma da corrente empirista inglesa, e Baumgarten, para representar o racionalismo estético alemão. Do primeiro, é destacada a tentativa de descrever as experiências estéticas segundo uma exposição fisiológica, ao passo que por meio do segundo é chamada nossa atenção para o tratamento estritamente lógico imposto ao domínio estético. Ao tomar cada uma dessas perspectivas como bandeiras que representariam, de um lado, as filosofias de Hume, Hutcheson e Kames e, do outro, as de Wolff, Leibniz e Meier, o autor assume o risco de pôr numa moldura de dimensões demasiado acanhadas as teorias de todos esses autores. Sua intenção, neste caso, foi a de prezar pelo aspecto elucidativo e situar, em linhas gerais, a posição estética de Kant, exatamente entre a dos empiristas e dos racionalistas:

\begin{abstract}
De acordo com as reflexões estéticas de Kant ainda no período pré-crítico, ambas as posições são insatisfatórias. A primeira, por reduzir o domínio estético às respostas simplesmente fisiológicas e empíricas, com cuja unanimidade não se poderia fundar uma universalidade do gosto que, por sua vez, depende tão somente de um princípio estético a priori. A segunda, por pretender uma definição contraditória da beleza como unidade produzida pelo pensamento cujo resultado seria sensível (GRUPILLO, 2016, p. 18).
\end{abstract}

Em suma, nas reflexões que antecedem a redação da Crítica da Rąão Pura (CRP), Kant já manifestava sua preocupação em fundamentar a universalidade do gosto, embora também percebesse a impossibilidade de o fazer por meio da enumeração de leis objetivas. Pensar o juízo estético como universal e, ao mesmo tempo, não amparado em princípios objetivos: eis um indigesto impasse que só teria chance de ser resolvido com as ferramentas inventariadas pela Crítica, a partir de 1781. Aquele método que ela inaugurou, de "exposição" e posterior "dedução" dos juízos é, conforme Grupillo tenta evidenciar, aplicado também na Crítica da faculdade do juízo (CFJ), precisamente sobre o juízo acerca do belo. 
"Quid fact??", questão que o pesquisador estampa no título do primeiro capítulo de seu livro, é a mesma que Kant se faz na Analítica Transcendental da CRP, quando pretende "expor" a composição dos juízos que formulamos. E perante os juízos estéticos, na "analítica do belo" acontece a "exposição" da maneira como nossos juízos de beleza são confeccionados, a saber, na tradicional forma "a é belo" com relação à "qualidade", "quantidade", "relação" e "modalidade". E, para seguir a classificação quádrupla dos juízos estéticos, como pede a divisão geral da analítica kantiana, Grupillo decompõe o primeiro capítulo de sua monografia precisamente em quatro partes.

Na primeira aprendemos que, quanto à "qualidade", o juízo de gosto é classificado por Kant não como "afirmativo", "negativo", ou "infinito", como previa a sua tábua dos juízos, mas, peculiarmente, como "desinteressado". Ora, um juízo que se pretenda exemplar, paradigmático, não poderia ser parcial, isto é, "interessado". Na segunda parte, encontramos todo o movimento de Kant para classificar o juízo estético como "universal", mas um "universal sem conceitos", no que tange à "quantidade"; fizesse recurso a conceitos, seria antes um juízo de conhecimento, não de gosto. Segundo a "relação", Kant toma o juízo estético como de "finalidade", porém, uma "finalidade sem fim", pois quem julga um objeto belo, segundo o filósofo, atribui a ele alguma finalidade intrínseca, embora, se o pudesse apontá-la, estaria no registro da ciência, não da estética. Por fim, no quarto subcapítulo da primeira parte de seu livro, Grupillo explica porque o juízo de gosto, quanto à "modalidade", é classificado como "apodítico", conquanto seu emissor exige sempre um assentimento irrestrito.

Destarte, o próximo passo da "exposição" é supor uma condição pela qual os homens poderiam anuir, desinteressada e universalmente, a um juízo estético, todavia sem recorrer a conceitos. É então que Kant insere o elemento fulcral do livro de Grupillo, qual seja, o "sensus communis", isto é, um sentido comum a todos os homens capazes de julgar. Em suma, o "conteúdo do juízo decomposto em suas partes segundo a qualidade, a quantidade e a relação como condições da possibilidade do juízo estético puro - são, então, reunidos em um princípio geral da faculdade de juízo estética" (GRUPILLO, 2016, p. 79). Somente com a pressuposição de tal sentido, é possível pensar num juízo 
estético com pretensão de validade universal e que atenda todas as condições impostas até aqui. Fica, assim, provado que o "sensus comunnis" é "condição de possibilidade" da emissão de um juízo sobre a beleza.

Ademais, o conteúdo da "analítica do belo" da CFJ, bem como a abordagem que Arthur Grupillo faz dela, são muito mais complexos do que a nossa descrição fez parecer. Que esta sirva para acentuar quão didática pode ser uma leitura do "O homem de gosto e o egoísta lógico", mas que não engane o leitor. O livro é carregado de citações, reproduzidas no original alemão quando são de Kant, e notas de rodapé explicativas aparecem sem economia. Em muitas delas, o autor se mostra atento e cuidadoso quanto à tradução de termos chave do vocabulário kantiano, caso mesmo do conceito de Gemeinsinn: após uma incursão em que coteja o original latino usado por Kant, sensus communis, e suas variantes francesa e inglesa, Grupillo resolve verter o termo por "sentido comum", embora com algumas ressalvas (cf. GRUPILLO, 2016, p. 76). Sua opção nos parece bastante acertada, conquanto as possíveis translações para "bom senso" e "senso comum" tenham, em nosso idioma, acepções que remetam mais à "sensatez" e ao " conjunto de leigos num determinado assunto acadêmico", respectivamente.

Grupillo também convoca ao debate os mais respeitados estudiosos do kantismo, como Jonathan Bennett e Henry Allison; alguns deles corroboram suas exegeses, outros recebem críticas e objeções. Enfim, o fato é que algumas passagens da monografia só podem despertar o interesse de pesquisadores engajados no estudo da estética de Kant, dado os requintes de minúcia exegética que elas assumem. É o que acontece, por exemplo, quando seu autor procura mapear, na filosofia kantiana, a transição do "princípio de finalidade das formas natureza" para sua formulação como "princípio de comunicabilidade" (Cf. GRUPILLO, 2016, pp. 24-27). Além disso, questões acessórias para o debate, mas centrais no pensamento kantiano, distribuem-se por todo o texto: os diferentes "graus de convicção" (opinião, crença e saber, cf. ibidem, p. 168), a distinção entre Schein vs. Illusion (aparência vs. ilusão, cf. ibidem, p. 183), e o problema do "solipsismo metodológico" do transcendentalismo kantiano são algumas delas. A gama de informações é tão 
variada que o leitor menos versado no kantismo, como um graduando, facilmente perde o fio-condutor da investigação.

A eventual confusão desaparece, no entanto, ao fim de cada capítulo, pois eles são sempre encerrados com uma retrospectiva do que foi tratado neles, e uma antecipação do que está por vir. No desfecho do primeiro capítulo, temos a pressuposição do sensus comunnis como condição da possibilidade da emissão de um juízo estético; além disso, o anúncio de que esse princípio deve, após sua "exposição", ser submetido a uma "dedução", nos moldes da filosofia transcendental de Kant. Com efeito, o "homem de gosto" precisa provar com que direito fala da existência de tal "sentido comum", caso não queira receber a justa alcunha de "egoísta lógico", aquele que, de tão certo do seu julgamento estético, dispensa os de outrem.

Em "Quid juris? - duvida o egoísta lógico", segundo capítulo do livro, Grupillo assume uma postura muito mais ativa e crítica. Após explicar o característico método transcendental kantiano de fazer deduções, o autor mapeará, na CFJ, os argumentos em que Kant supostamente deduz o "sensus comunnis". É aí que Grupillo dá sua contribuição mais original. Ele destrincha os argumentos dos $\int 21$ e 38 da Crítica da Faculdade do Juízo, translada cada um deles para a forma lógica e analisa as premissas à luz daquele binômio "necessário e suficiente”, que é tão caro aos analíticos. Quem quer que acompanhe a decomposição e rigorosa análise do argumento do $\ 21$ (cf. GRUPILLO, 2016, pp. 96-100) não terá dificuldades em perceber, junto com Grupillo, que tal argumento é falacioso; os mais afeitos à lógica também concordarão com o exegeta que se trata da falácia do "ilícito menor". No argumento do $\int 38$, uma segunda tentativa de provar o direito à pressuposição do "sentido comum", Kant não obtém mais sucesso. Mais uma vez, sob o extenso crivo da lógica formal que Grupillo lhe imputa, o argumento se mostra invalido (cf. ibidem, pp. 119- 131). Como conclusão desse segundo capítulo, temos o fracasso de Kant em deduzir o princípio de comunicabilidade na CFJ, e a proposta de uma hipótese: tomar o "sensus communis" como um princípio regulativo, isto é, como uma daquelas ideias da razão, tal qual "Deus", "alma", "universo", que não encontram nenhum correspondente na realidade. 
Ademais, o pesquisador ainda investiga, no terceiro e último capítulo de seu livro, como o princípio de comunicabilidade é trabalhado na Crítica da Razão Pura. Ele acaba por concluir que, embora se tenha provado a "possibilidade lógica" do "sentido comum", em ocasião alguma foi deduzida, satisfatoriamente, sua "possibilidade real". O máximo que Kant conseguiu foi dar a tal princípio o status de simples ideia da razão especulativa, confirmando aquela hipótese levantada por Grupillo. No argumento kantiano, basicamente pragmático, é mais vantajoso à razão pressupor que todos os homens possuem uma faculdade que permite a comunicabilidade entre eles. Definitivamente, a

hipótese de que o princípio de comunicabilidade seja constitutivo está simplesmente descartada. Sendo assim, (...), como princípio regulativo, a pressuposição de um 'sensus commuis' manifesta um interesse superior da razão pela unanimidade do modo de sentir, talvez, porque interessa à sistematicidade da razão não apenas a validade dos juízos de conhecimento, mas também a comunicabilidade do sentimento que os acompanha" (p. 190).

O gosto seria, então, uma faculdade fictícia a ser cultivada; e o desinteresse, bem como a aceitação de que o belo foi feito com alguma finalidade que jamais se poderá descobrir, são indicativos do caminho que o cultivo do gosto deve seguir.

O livro traz ainda, em apêndice, uma "Breve história do conceito de sensus communis". Aí podemos perceber, dentre outras coisas, como esse sentido passou de seu uso restrito a questões morais e cognitivas, para sua inserção nas investigações estéticas. E somente nesse apêndice aparece alguma alusão à teoria estética de Kant sobre o "feio" (Cf. GRUPILLO, 2016, p. 212). Grupillo recomenda, por fins pedagógicos, a leitura desse suplemento logo após a do capítulo I de seu livro, pelo que o restante do conteúdo se tornaria de mais fácil compreensão.

Num "Pós-escrito", o pesquisador faz menção a dois livros que tiveram grande impacto no seu pensamento sobre estética, e com os quais ele teve contato apenas depois de finalizar a redação de $O$ homem de gosto e o egoísta lógico. Tratam-se dos livros Non satis est, de Silke Kapp, e os Principia Ethica, de Georg Edward Moore. Nesse anexo, temos ainda uma eloquente metáfora que finaliza toda a investigação: o sensus communis de Kant seria como uma gramática, que 
Perspectiva Filosófica, vol. 44, n. 1, 2017

"regula, mas não constitui o uso da linguagem. Assim como as regras da etiqueta regulam, mas não constituem, o ato de sentar-se à mesa" (GRUPILLO, 2016, p. 219).

Enfim, Arthur Grupillo escreve um livro muito técnico e no qual se esforça por uma linguagem sofisticada, inviabilizada, a maior parte das vezes, pelo truncado vocabulário kantiano ao qual está sempre apegado. O escrito merece a leitura de pesquisadores especializados nesse tema; é pertinente que meçam o alcance das críticas feitas às deduções do sensus communis, e avaliem a consistência de reduzir tal sentido ao estatuto de princípio meramente regulativo. Graduandos, por sua vez, encontrarão no manual uma leitura instrutiva e desafiadora a respeito da estética de Kant. Mas, caso o estudante ainda não tenha familiaridade com a teoria e a terminologia desse filósofo, $O$ homem de gosto e o egoísta lógico não é a melhor opção para começar essa instrução. 